\section{Showing, Telling, Understanding: Musings on Popularization}

Emmanuel Ordóñez Angulo

The Viewpoint column offers readers of the

Mathematical Intelligencer the opportunity to write

about any issue of interest to the international

mathematical community. Disagreement and

controversy are welcome. The views and opinions

expressed here, however, are exclusively those of the

author. The publisher and editors-in-chief do not

endorse them or accept responsibility for them.

$>$ Articles for Viewpoint should be submitted to one of the editors-in-chief, Karen Hunger Parshall (khp3k@virginia.edu) or Sergei Tabachnikov (tabachni@math.psu.edu).

\section{1}

T oward the end of Jorge Luis Borges's story "The Aleph," a man tries to explain to another the notion of "a point that contains all points." His efforts, naturally, fail (it is a perplexing idea, and they are speaking over the phone). But the baffled character-a stand-in for the writer, also called Borges-learns that his interlocutor has experienced this infinite thing himself. So he could just show him. "I'll be right over," says Borges before the explainer can try again. "I want to see it." Once they have met, Borges is ushered by the other man into his home's basement, where the Aleph is supposed to be, and walked through a curious procedure that Borges observes with incredulity ("I followed his ridiculous instructions"). Then, at last, he too sees it:

I shut my eyes-I opened them. Then I saw the Aleph. I arrive now at the ineffable core of my story.

... How can I translate into words the limitless Aleph,

which my floundering mind can scarcely encompass?

Channelling, as it turns out, not just Wittgenstein but also Borges, the philosopher A. W. Moore writes in The Infinite [9] that infinity is the kind of thing one cannot grasp through words. To know it, one needs to "be shown" it. The obscurity of this thought is no surprise: "In the closing pages of the [Tractatus]," Moore writes, "Wittgenstein identified what cannot be put into words (what can be shown) with what is mystical" [8, p. 193]. Yet the idea that infinity-and, by extension, mathematics-connects to arcane questions, which is to say to philosophy, dates back to the cradle of Western thought. In the Republic, Plato praised the power of mathematics to turn the soul toward the abstract, which he believed to be more real than the empirical. In the Physics, Aristotle linked mathematics to puzzles having to do with time and with the difference between what is and what can be. Moore himself thinks that our awareness of infinity stems from our self-consciousness; hence, "in thinking about the infinite, we are thinking, at a very deep level, about ourselves" [8, p. xviii]. It would be difficult not to feel the pull of this inkling. "Infinity ... connects instantly to big, personal questions about life and death, power and control, the beginning of time and the end of the Universe," the science writer Sarah Scoles writes [11]. Hence, she tells us, it is important for students "to experience math—not just hear about it, as typically happens in the classroom-to understand it." Scoles is talking, unlike Moore, of a mathematical concept of the infinite, not a mystical one. In mathematics, infinity is understood, at its most basic, as the concept of a set with more elements than any finite set, an arguably less obscure notion than the "metaphysical or theological" notion 
discussed by Moore. But there is still a kinship between the metaphysical and the mathematical notions of the infinite. Both are difficult to capture with words. Just as language is necessarily limited compared to the theological infinite, "that which is absolute, total, perfect," it is also finite, whereas the mathematical infinite is "that which is endless, unlimited ... immeasurable" [8, p. xiii]. This problem (call it linguistic) is only an indication of a more basic one (call it epistemological). Just as our powers of discourse are limited, so are our cognitive powers.

At the same time, the infinite is one of the most tantalizing mathematical and philosophical concepts. "From the beginning of its history," Moore writes, "the infinite ... has aroused suspicion. This is partly because it can never be encountered in experience, partly because it is riddled with paradoxes" [8, p. xiii]. This allure adds to the peculiar problems the infinite presents for those who, like Borges's character, seek epistemic access to it, those who want to "see" it. But what exactly does the injunction to show rather than tell-to provide students "mathematical experiences," as Scoles puts it-amount to?

That is, no doubt, a complex question. In this short commentary I only gesture toward an answer. To do that, I begin by proposing a notion of mathematical understanding; then I take a brief look at four approaches to the task of teaching infinity to mathematical novices-four approaches, that is, to "popular" philosophy and mathematicsand assess whether they provide such an understanding. But I don't mean this to be a recommendation for or against any author. Rather, I want to submit the idea that mathematical understanding is an important dimension of popularizing efforts, all of which can be valuable, to be sure, along other dimensions.

\section{2}

Usually traced back to the cognitive achievement the ancient Greeks called episteme, the notion of understanding can be viewed as the end of a process of reasoning. If one knows that all men are mortal and that Socrates is a man, one can understand the fact that Socrates is mortal. But episteme is sometimes translated as "knowledge." What is the difference? To glance out the window is one way of knowing the color of the sky: perhaps it is blue, if it is a cloudless day, or red, if you are near nightfall. Another way to know this is simply to be told. There is no reasoning involved in either of these methods. But do you thereby understand why the scattering of blue light from the sun causes that appearance, or why, under certain conditions, it does not outweigh the scattering of red light? Only if one knows these further facts does one have "knowledge without qualification" of the target fact, as Aristotle would put it. To know that something is the case without knowing why is to have something like superficial or partial rather than full-fledged ("unqualified") knowledge of it, a kind that falls short, in any case, of understanding.

So, achieving episteme of a mathematical fact requires knowing why it obtains, what other facts are behind it. The standard form of explanation in mathematics - the way of relating explanatory facts to the fact they explain-is proofs. In this, it resembles philosophy. There is no single view on what the business of philosophy is, but one such plausible view is that it is reasoning. Arguments, or proofs, are typically the vehicle. Not all proofs are explanatory, and not all explanations involve proofs. Proofs by mathematical induction are often regarded as nonexplanatory, while visual explanations (an animation of squares growing from each side of a right triangle to explain the Pythagorean theorem, for example) need not constitute proofs. But generally speaking, scientific explanations, and mathematical explanations in particular, do tend to take the form of arguments-which is another term for proofs. A proof or argument is a series of steps that take you from a set of propositions (the premises or assumptions) to a target proposition (the conclusion or result) under the guidance of rules of inference (the logic that guarantees that from a certain proposition, another follows). The job of a proof is thus twofold: on the one hand, it proves the target fact, and on the other, it explains it via the assumed (or previously proved) propositions.

Take the fact that there are infinitely many positive whole numbers. In order to grasp this, one must grasp the fact that every such number has a successor. If succession is understood such that indefinitely iterating it gives a sequence with no repetitions, the result is a set with more elements than any finite set, which is what we mean when we say that the set of positive whole numbers is infinite. So the fact that every positive whole number has a successor explains, at least in part, the fact that there are infinitely many of them.

To see beyond the sheer factuality of things - to reach episteme of them-has long been a task of philosophy. Arguments don't make us aware of the explanatory and explained facts in isolation but of how they "hang together," as Wilfrid Sellars puts it [12, p. 37]. This suggests a helpful metaphor. To understand a fact is to have the ability to manipulate the arrangement of explanatory and explained facts in our minds, like a theoretical mobile. What, for example, if not all whole numbers had a successor, or if adding a positive number to another didn't always result in a new number? Because these are the tophanging facts, changing them while holding the stringsthe rules of inference-fixed changes the low-hanging facts, the results. So, proofs don't engage only our deductive reasoning but also our imagination, that faculty in charge of dealing with what is not but could be. The difference between being "told" a mathematical result and being "shown" how it hangs together with its explanation is the ability to dismantle these facts in one's own mind and assemble new arrangements.

\section{3}

Engaging, as it does, both reasoning and the imagination, the experience of working through a proof compares to witnessing someone describe its steps (as typically happens in the classroom), as watching a film compares to reading the film's plot, or as figuring out a route on one's mental map compares to hearing instructions from Google Maps. 
That understanding philosophy and mathematics involves this level of immersion is inconvenient for written media. Ironically, the power of philosophical and mathematical insight is bound to tempt enthusiastic writers to attempt to share them. Those writers, called "popularizers," face the challenge of doing justice to both the clarity mathematics calls for and its distinctive reward, a "chill of understanding," as Scoles puts it [11]. But where popular mathematics's closest kin, popular physics, deals with the nature of concrete, if distant, things (the nature of space and time, the structure of the universe), the stuff of mathematics and philosophy is intangible abstractions. Popular physics might be mind-bending because it challenges the laws of nature we know and love; mathematics and philosophy are because they are not constrained by those laws.

That makes it seem a good idea to keep a popular book about philosophy and mathematics on the easy side, to tell the reader what the results mean (what infinity means, for example) without exposing them to the details (without having them work through the proofs). Let me propose four categories of books according, on the one hand, to how immersive in argument they are for the reader, and on the other, to whether the author himself is fully immersed-whether he is trained as a philosopher or mathematician.

Consider one clear case of a nonargumentative book by a nonacademic, Jim Holt's When Einstein Walked with Gödel [3]. It treats such diverse topics as Kurt Gödel's incompleteness theorems, category theory, topology, fractals, and computability within mathematics; in philosophy, it treats morality, Saul Kripke's theory of reference, and what Holt calls "the theory of truth." Additionally, there is juicy gossip about philosophers' and mathematicians' lives: Ada Lovelace's scandalous squandering, Kripke's scandalous (alleged) intellectual theft. The cost of such breadth is depth, as exemplified by Holt's discussion of prediction. He focuses on the prediction of the life span of phenomena, which he claims can confidently be predicted based on how long the phenomena have been around at the time of estimation. This is because "[i]f there's nothing special about our perspective, we're unlikely to be observing any given thing at the very beginning or the very end of its existence" [3, Chapter 4]. But the work Holt is drawing from included the calculation (in 1993) that the journal Nature had a $95 \%$ chance to continue publishing for a period of between 3.15 and 4,800 years. How meaningful is this as an estimate? Moreover, Holt's predictions are probabilistic, and he doesn't clarify how probability and confidence are related. Given the negligible probabilities of an essayistic piece like this getting published in a serious journal, should I be confident it won't be published?

But it would be a mistake to expect a nuanced treatment of probability and prediction-both classics of the philosophy of science-in a work designed to be painless, even gimmicky. Holt's writing bustles with superlatives: the emergence of consciousness is reportedly "the last frontier of science" [3, Part VIII]; Richard Rorty, "probably the most prominent 'truth denier"'[3, Chapter 24]; cogito ergo sum, "the most overconfident judgement in history" [3, Part VIII].
This coarseness risks hurting philosophical sensibilities. In his characterization of Platonism, the view that the objects of mathematics are no less real or mind-independent than the objects of study of the natural sciences, Holt ascribes to Platonist philosophers the mystical belief that mathematicians can "claim insight into an eternal realm of abstract forms transcending the ordinary world we live in" [3, Preface]; that they can reach out, with their earthly senses, into a "realm ... hovering over the empirical world-a sort of Platonic heaven" [3, Chapter 12]. Platonism is a more sophisticated view than this, or at least it can be: there are various versions. The existence of mathematical objects needn't entail extravagant metaphysics. Holt's complaint thus speaks to a view few Platonists have held since Gödel, whose hard-line version of it relied on an obscure faculty that he likened to sense perception but deemed attuned specifically to abstract objects: "[b]ut mathematicians, like the rest of us, think with their brains," Holt writes, "and it's hard to understand how the brain, a physical entity, could interact with a non-physical reality" [4]. No Platonist today-myself included-would deny this.

The truth is that there is no faulting Holt for these slips. $\mathrm{He}$ is an enthusiast, after all, a magazine writer keen to convey "the depth, power, and sheer beauty ... of the most thrilling (and humbling) intellectual achievements I've encountered in my life" [3, Preface]. An alternative for a writer with the academic credentials to keep worries about rigor at bay is to present the ideas with the help of narratives, in a way closer to historical fiction, say, than to popular history. This is the strategy of Douglas Hofstadter's legendary Gödel, Escher, Bach [2], a nonargumentative book written by an academic. Blunders are not easily found here. The thing with Hofstadter is that he gives little credit to the reader. He invests most of his creative prowess going out of his way to present mathematical results through quirky, witty devices; of note are his puns and his allegories. Consider his presentation of the problem of selfreference, the result of which is a breakdown in language (or in the underlying logic; the jury is still out). In Gödel, Escher, Bach, this takes the form of the problem that would arise if records were designed to physically break record players. But records are artefacts—so who would design such a thing? How long would a record have to be played before it performed its record-player-breaking function? Yet, if that is its function, does it make sense that it can be played at all in the first place?

The truth is that here, too, there is no faulting Hofstadter for having fun with the parallels he finds between abstract and (imagined) concrete phenomena. This fun comes at the cost, however, of sacrificing the pattern itself, the abstract idea, and its own details.

Now, there is another side of things to consider. Holt has brought the subject of philosophy and mathematics to readers of general-interest magazines such as the New Yorker, where he is often published, a feat no doubt due, precisely, to his uninvolved treatment of the ideas. Hofstadter's book is single-handedly responsible for plenty of philosophers' decisions to enter academia. These are things to celebrate, and both the mathematical and philosophical professions are better off for them. Yet one thing these 
books do not seem equipped to do is to provide genuine, if elementary, understanding of the material. Perhaps they provide some acquaintance with it, or playful illustration. But an ability to see how a given set of facts explains other facts-an ability to see how they hang together-is something that requires imaginative and intellectual engagement. Surely, there are readers who do not pick up this sort of book with the aim to be introduced to these topics-not to be "told" about them-but who already are intrigued and are now exclaiming, like Borges, "I want to see it!" For the popularizer, this means that there is less to gain from clearing the path for the reader than from working with her through the travails.

But the alternative of showing how the facts hang together is riskier. The best-known attempt I know is David Foster Wallace's Everything and More [13], a "pop-technical" introduction, as he puts it, to the mathematics and philosophy of the infinite. The riskiness shows. By most lights, the effort failed. The reasons are numerous. One reviewer, Michael Harris, a mathematician at the University of Paris, said that the book "lacks a clear sense of direction" [1, p. 632]. This much is true: Wallace swerves between technical and historical exposition in a way that doesn't make clear whether one should concentrate on understanding the development of the ideas or the ideas themselves. Sometimes, this reviewer added, what is exposed is irrelevant anyway-both historically and mathematically. The ostensible focus of the book, the development of set theory, was a side effect of Georg Cantor's work on a problem of "little obvious metaphysical interest" [1, p. 635], and of a greatly reduced level of mathematical importance since Cantor's day. Yet Wallace spends nearly half his book preparing the reader for it. Philosophically, the book doesn't fare much better. Another reviewer (the University of Oxford philosopher A. W. Moore) noted that Wallace overstates-in fact, misleads about-the inaccuracy of Aristotle's views on infinity. "Aristotle manages to be sort of grandly and breathtakingly wrong, always and everywhere, when it comes to infinity," Wallace breathtakingly overstates [9, p. 143]. Yet the shift from an Aristotelian view of infinity to a Cantorian one-from a "potential" view to an "actual" oneis much subtler than this suggests, and recent developments in the philosophy of mathematics have raised the possibility that the two might be less far from each other than is often presumed. ${ }^{1}$

It is clear that this book belongs to the third category: the one that does not spare the reader the work of argument, but that is written by someone who didn't have full control of the material himself. Even though Wallace spent time as a doctoral philosophy student at Harvard and had "developed a jones for mathematics" in high school [14, p. 68], he was neither a trained mathematician nor a philosopher. What he was is an otherworldly writer, a quality that shows throughout the text. Unfortunately, an investment in style works, in this subject matter's case, to its detriment. Most reviews noted how Wallace's cumbersome informality ("pretty much," "sort of"; calling a mathematical device a producer of "schnitt sandwiches") resulted in a book that requires not ornament but transparency, neatness.

There is, to be sure, little use for a negative review of an old book by a dead writer (of whom the reviewer is an admirer, at that), but surveying the shortcomings of these three approaches puts one in a position to understand (even if not to agree with) a general pessimism about the very business of popular abstract writing. Wallace's failure to provide not bedtime reading but genuine understanding seemed to the critic Adam Mars-Jones inevitable. "There's no such thing as an opsimathematician-someone who develops a passion for the mysteries of numbers in adulthood," he wrote [6]. "You either get it young or you don't get it." When they don't shy away from mathematical complexity, authors risk being "absurdly demanding," in Mars-Jones's words. When they skip over it, they risk frustrating mathematical understanding and, consequently, whatever philosophical insight they might hope to bring out from it. If an author thinks there is balance to strike here, as Wallace seems to have thought, then, for his noble intentions, "he's deluded."

Mars-Jones goes on:

In some ways, Wallace's is an attractive delusion, more so than the Beautiful Mind approach which assumes that a breakthrough in game theory can only be dramatised by showing a nerd devising a technique for getting the girl in the college bar. But it's still a delusion.

\section{4}

A Mexican philosopher based at MIT has taken up MarsJones's gauntlet. Agustín Rayo first got into philosophy to collect material that might help him to fulfill his original dream: to become a filmmaker. Although, evidently, philosophy didn't let him go in the end, Rayo continued to feel the itch to share what he found with the public. From 2008 to 2012, he contributed bimonthly columns on the intersection of philosophy and mathematics to the Spanish edition of Scientific American, a magazine called Investigación y Ciencia. There, he seemed to strike the delicate balance between rigor and accessibility that has long proved so elusive. Eventually, these columns became the basis for a course at MIT, Paradox and Infinity, designed to be panoramic rather than advanced in spirit; then they made their way to an online version, and finally to Rayo's first trade book (he has a prior academic one), On the Brink of Paradox: Highlights from the Intersection of Philosophy and Mathematics [10].

It is a clear case of the fourth category. The contents take the reader on a hike across the philosophical landscape.

\footnotetext{
${ }^{1}$ One reason to think that they are far from each other has been the assumption that classical logic can work only with an actual conception of infinity, whereas the notion of potential infinity requires intuitionistic logic. Øystein Linnebo and Stewart Shapiro [6] have argued against this. They have shown that potential infinity can be made sense of with classical logic, and that propositions involving potential infinity-propositions expressed, that is, with a modal vocabulary-can be proved to be equivalent to propositions employing an actualist conception.
} 
The first part, which deals with infinity, places us at the peak of abstractness. It introduces mathematical phenomena and then builds up philosophy on top of it. In the second part, which deals with decision, probability, and set theories, we find ourselves on ground level. Mathematics is not the object of study here but a tool to examine recognizable human problems. The third part is somewhere in the middle of that range. It deals with computability and Gödel's theorem (by which singular Rayo means the incompleteness theorem and its "corollary," the second incompleteness theorem). The connecting thread is the idea that progress in these topics has been triggered by a glitch in, precisely, our understanding of them, or in other words, by paradox. The quest for episteme, that strange beast, is for Rayo not just the end of the book but what fuels its narrative.

The book is at its best in threading philosophy and mathematics in its exposition of Gödel's theorem. A comment on this section of the online course read, "I am already so impressed by this section that I decided that simply taking notes in a journal was not enough, and I wrote on my closet door. This really does feel like "the big thing." Another responded, "Awesome! Closet-worthy!" Closet-worthiness does not arise from Rayo's presentation of the theorem alone. It is simply difficult to think of a topic where mathematics and philosophy are more intimately fused together. The issue of self-reference is fruitfully treated as part of the larger issue here, of which the mathematical and philosophical significances are-again, fruitfully-distinguished from the start. Mathematically, Gödel's theorem tells us that "there is a precise sense in which no finite computer program could possibly encapsulate the whole of arithmetical truth" [10, Chapter 10]. Philosophically, it suggests that "our mathematical theories can never be established beyond any possibility of doubt" [10, Chapter 10].

Rayo offers a clue to the substance of these claims anecdotally [10, Chapter 10]:

Sometimes our best theories of the natural world turn out to be mistaken. ... Many years ago, when I was young and reckless, I used to think that mathematical theories were different: I used to think that they could be established beyond any possibility of doubt. ... Gödel's theorem has convinced me that the exclusion of all possible doubt is just as unavailable in mathematical theory as it is in a theory of the natural world.

Further philosophical questions suggest themselves. If certainty is a matter of exclusion of doubt, of knowing something to be (or not) impossible, then what can we really be certain of? Even accounting for various degrees of confidence, do we know that we have two hands, let alone that the Sun will rise tomorrow? Is it impossible, in other words, that we are brains in vats hallucinating body parts, or that regularities we saw in the past are not repeated in the future?

\section{5}

There is, perhaps, a fifth category to mention. That of a book written by a nonacademic who is fascinated with mathematical and philosophical ideas and thus wants to convey his fascination. Witness When We Cease to Understand the World [5], by Benjamín Labatut, a web of narratives that sprawl around the physical and metaphysical obsessions of a number of twentieth-century mathematicians, including Alexander Grothendieck, Werner Heisenberg, and Erwin Schrödinger. Labatut's book is on the opposite end of the spectrum from Rayo's. It does not seek to deliver understanding of its subjects' theories but rather to pull us into the lived experience of their daily grind, to tell us, rather than show us, about their obsession with paradox and infinity, with the "way in which the universe is organized," as Labatut puts it [5, Chapter 2]. The experience of reading Labatut is the converse of reading Rayo. Without the burden of explanation, Labatut is free to devote himself to the chaos and the beauty not of the ideas but of the concrete lives of those who grappled with them.

The lesson I want to bring out is that the understanding of such abstract matters is best treated as a separate goal from literary engagement, or that such a treatment can be good practice. But perhaps this result is biased. My (extremely brief, and extremely selective) survey is of books about what probably is the epitome of what lies at the intersection of mathematics and philosophy, the notion of infinity, and the ideas here, both mathematical and philosophical, are delicate and wild. It is difficult to think of a subject in which one's bandwidth is more severely put to the test, hence the need to tread carefully, rather than casually, through such material. Acknowledging this may help to respond to a natural objection: is a book that takes Wallace's—now Rayo's_- "absurdly demanding" approach really a "popular" one? Holt thinks not [3, Chapter 11]:

Wallace's effort ... can't quite be described as popularization. Wallace assured the reader that it is "a piece of pop technical writing" and claimed that his own math background didn't go much beyond high school. And yet he refused to make the usual compromises. Everything and More is sometimes as dense as a math textbook .... I have never come across a popular book about infinity that packs so much technical detail.

Yet to "compromise" on the detail is to change the subject. A book about the lives of philosophers and mathematicians, about "watered-down approximations" of their ideas (Rayo's words [10, Preface]), or about the fictions inspired by them is not a book about the ideas themselves. A reader who seeks understanding of these subjects is simply a different target from one who seeks to hear about others' intellectual and aesthetic relation of them. Mars-Jones makes the point himself when he says [7]:

If ... there is a series of chords in Britten's Billy Budd which move me every time I hear them ... and I wish to share my ecstasy by writing a book, then I can either produce a concise history of Western music, of opera as a form, of Britten's development and 
psychology, or I can simply wallow in my impressions and hope to make them contagious, but I can hardly do both.

Quite right. A popularizer's options are to tell others about what moves them or to directly show it to them. No doubt this is Wittgenstein's fault, but if telling is the enthusiast's choice, showing is the philosopher's. The reward for the reader is not just episteme. It is a trope among all these authors that their prime motivation is the beauty of the ideas: Holt speaks of the "sheer beauty of the ideas" as one of his considerations to write his book [3, Preface]; Wallace's goal was "to make the maths beautiful-or at least to get the reader to see how someone might find it so" [13, p. 2]. Rayo expresses the same sentiment: "the goal is to introduce you to some exceptionally beautiful ideas" [10, Preface].

Wittgenstein placed the aesthetic within the sphere of the mystical_of what can only be shown. If this is right, then a mystical experience might turn out, after all, to await the seriously interested reader. Kant taught us that the appreciation of beauty, just like the understanding, involves the activity of the imagination. And it is only by confronting the object itself-the beautiful thing or idea-that the imagination can take it in. This is because it is not in fact in the object but in our experience of it, the extended process of taking the object in, where beauty lies. When it comes to art or nature, this means one has to actually perceive the thing with one's own senses; when it comes to abstract ideas, it means that one has to do the reasoning with one's own mind. The delusion is not in thinking that the rewards can be reaped beyond a certain age or the classroom but in what Holt calls the "cocktail party" chat, "with a few swift pencil strokes on a napkin" [3, Preface].

To close, with apologies, with personal anecdote: MarsJones is simply wrong about the nonexistence of "opsimathematicians." Yours truly is living proof. My own trajectory has been the opposite of Rayo's. Having quit a career-an incipient career, not much to quit-in filmmaking, I decided to study philosophy, and early on I spent a summer as philosopher-in-residence of the London Mathematical Laboratory. The learning curve was steep. Soon, I realized that my colleagues' attempts to explain mathematics to me would be fruitless unless I myself worked through the arguments. Watching them tell me about them on the white board did nothing much. An academic introduction would have been of no use to me, however: my interest was serious, but my conceptual equipment was less than an amateur's.

So here is another way of seeing the significance of serious-that is, argument-heavy-popular books of philosophy and mathematics. They needn't only serve the purpose of recruiting new adepts, as Holt's and Hofstadter's books might do. They can also cater to the interest of already keen readers, and so actually have them do philosophy and mathematics, albeit at an appropriate level of sophistication. A popular book might thus be bad, or good, not absolutely but depending on what one wants to get from it. If one seeks episteme (and the aesthetic experience that comes with it), a book that engages in argument is better than one that doesn't. If one wants to be told a story, a book of narrative might be better than one that swerves from theory to anecdote without fully probing either. Does this mean that there is no way for one book to do both? Of course it does not mean that. If the human mind cannot be mechanized, as Gödel's theorems seem to imply, then its outputs are unpredictable, which means that this question, and the realm of possibilities for popular writers, remain open. Both aspiring opsimathematicians and the general public stand to benefit from ever new attempts to provide both a rich literary experience and episteme; and perhaps, one may hope, to prove this essay wrong.

\section{OPEN ACCESS}

This article is licensed under a Creative Commons Attribution 4.0 International License, which permits use, sharing, adaptation, distribution and reproduction in any medium or format, as long as you give appropriate credit to the original author(s) and the source, provide a link to the Creative Commons licence, and indicate if changes were made. The images or other third party material in this article are included in the article's Creative Commons licence, unless indicated otherwise in a credit line to the material. If material is not included in the article's Creative Commons licence and your intended use is not permitted by statutory regulation or exceeds the permitted use, you will need to obtain permission directly from the copyright holder. To view a copy of this licence, visit http://creativecommons. org/licenses/by/4.0/.

\author{
Emmanuel Ordóñez Angulo \\ University of Oxford \\ Oxford \\ UK \\ e-mail: emmanuel.ordonezangulo@philosophy.ox.ac.uk
}

Editors' note: See Andrew Simoson's review of Augustín Rayo's book On the Brink of Paradox in the present issue.

\section{REFERENCES}

[1] M. Harris. A sometimes funny book supposedly about infinity. Notices of the American Mathematical Society 51:6 (2003), 627633.

[2] D. Hofstadter. Gödel, Escher, Bach. Basic Books, 1980.

[3] J. Holt. When Einstein Walked with Gödel. E-book, NY: FSG, 2018.

[4] J. Holt. Mathematics on ice. London Review of Books 31:16, 2009.

[5] B. Labatut. When We Cease to Understand the World. E-Book, New York Review Books, 2020.

[6] Ø. Linnebo and S. Shapiro. Actual and potential infinity. Noûs 53:1 (2019), 160-191. 
[7] A. Mars-Jones. Two + two $=$ phwoar. The Guardian. Retrieved from https://www.theguardian.com/books/2003/nov/30/scien ceandnature.features, 2003.

[8] A. W. Moore. The Infinite. Oxford University Press, 1990.

[9] A. W. Moore. How to catch a tortoise. London Review of Books 25:4, 2003.

[10] A. Rayo. On the Brink of Paradox: Highlights from the Intersection of Philosophy and Mathematics. E-book, MIT Press, 2019.

[11] S. Scoles. How thinking about infinity changes kids' brains on math. Aeon. Retrieved from https://aeon.co/ideas/how-thinkingabout-infinity-changes-kids-brains-on-math, 2016.
[12] W. Sellars. Philosophy and the scientific image of man. In Frontiers of Science and Philosophy, edited by Robert Colodny. University of Pittsburgh Press, 1962.

[13] D. F. Wallace. Everything and More. Weidenfeld \& Nicolson, 2003.

[14] D. F. Wallace. Tennis, trigonometry, tornadoes. Harper's, December 1991.

Publisher's Note Springer Nature remains neutral with regard to jurisdictional claims in published maps and institutional affiliations. 